\title{
The Canadian Lung Association/Canadian Thoracic Society and tuberculosis prevention and control
}

\author{
Richard Long MD*
}

$\mathrm{T}$ he jubilee of the Canadian Thoracic Society (CTS) provides us with an opportunity to reflect on the organization's roots and the meaning of those roots to contemporary tuberculosis prevention and control, as well as global respiratory health. It is worth our while to recall that the Canadian Lung Association (CLA) and its medical arm, the CTS, have a direct lineage to parent organizations in the fight against tuberculosis in Canada.

The beginnings of an organized effort to deal with [tuberculosis in Canada] were made in Ontario in 1896, when Sir William Gage founded the National Sanitarium Association for the purpose of building sanatoria for the treatment of tuberculosis. Its first sanatorium, the Muskoka Cottage Hospital, which opened the following year, was a step in the right direction for sufferers from the disease, who previously had to seek sanatorium treatment outside the country. Two other organizations were formed in the next few years - The Toronto Association for the Prevention of Consumption and Other Forms of Tuberculosis in 1898, and the Ontario Association for the Prevention of Consumption and Other Forms of Tuberculosis in 1900 - but it soon became apparent to concerned individuals that in order to achieve success the attack would have to be made on a national level. Dr Peter Bryce, Dr EJ Barrick, and the Reverend ES Eby, along with others who were interested, then took steps to organize the Canadian Association for the Prevention of Consumption and Other Forms of Tuberculosis (1).

From the beginning, this was a hybrid organization of committed laypersons and medical professionals who advocated tirelessly on behalf of tuberculosis patients for a sustainable infrastructure, government responsibility, education and research. It intuitively grasped the significance of Sir William Osler's prophetic words - "Tuberculosis is a social disease with a medical aspect" - and laboured to generate a community-based response to the disease. In 1923, the Canadian Association for the Prevention of Consumption and Other Forms of Tuberculosis was renamed the Canadian Tuberculosis Association. In 1946, at the annual meeting of the Canadian Tuberculosis Association, a program committee was struck to develop a medical section in which items of pure medical interest could be discussed. In due course, the
Canadian Tuberculosis Association became the CLA and its medical section became the CTS. The 1940s and early 1950s also saw the discovery of the revolutionary new drugs that would change the course of history. Accordingly, the mid-20th century became a turning point in the life of the CLA/CTS, as well as in tuberculosis prevention and control. In the present essay, a thesis is advanced, respecting the broader implications of tuberculosis control; sequential events central to that thesis are identified as having occurred in either the first or the second half of the 20th century.

\section{TUBERCULOSIS PREVENTION AND CONTROL \\ IN THE FIRST HALF OF THE 20th CENTURY}

Although there is a great deal to be said of this period, two aspects are of particular interest to Canada and the CLA/CTS: the enthusiastic adoption of sanatorium treatment and bacille Calmette-Guérin (BCG) vaccine. The epidemic of tuberculosis in western Europe was synchronous with the industrial revolution, and the overcrowding, inadequate housing and poor hygiene attendent on the mass movement of labour into an urban workforce. The epidemic peaked in the first half of the 19th century, and out of it grew current concepts of hygiene, sanitation and, ultimately, the germ theory of disease. By the mid-1800s, reformist opinion had evolved sufficiently to welcome the first institution for the treatment of tuberculosis, the German physician Hermann Brehmer's sanatorium at Göbersdorf, Germany, in the mountains of Silesia (2). The movement sprang from humanitarian ideals and not scientific doctrine. The idea spread rapidly across all of Europe and into North America $(3,4)$. Admission to sanatoria came to depend on the recovery of tubercle bacilli on smear or culture and a compatible chest x-ray abnormality (Mycobacterium tuberculosis was discovered in 1882 and chest $\mathrm{x}$-rays in 1895). In Canada, the extent to which sanatorium treatment became available is set out in the reports of the Dominion Bureau of Statistics (1) from 1937 to 1971. Comparative tables show how the total number of persons in sanatoria reached 17,364 in 1953, the peak year, which was just before the new drugs were beginning to take effect.

Sanatorium treatment was as much about the individual patient (fresh air, nutrition, rest and rehabilitation) as it was about control of the disease in society (education, public support and the sequestration of infectious patients), and involved a new relationship between the medical profession and the public (2). Only after the fact was bedrest and 'resting' the lung

* Chair of the Canadian Tuberculosis Committee of the Public Health Agency of Canada, Past Chair of the Tuberculosis Committee of the Canadian Thoracic Society

Correspondence and reprints: Dr Richard Long, Tuberculosis Program Evaluation and Research Unit, Room 8325, Aberhart Hospital, 11402 University Avenue, Edmonton, Alberta T6G 2J3. Telephone 780-407-1427, fax 780-407-1429, e-mail richard.long@ualberta.ca 
TABLE 1

Bacille Calmette-Guérin (BCG) vaccination of Indian infants in Saskatchewan (born from October 1933 to December 1945 at the Qu'Appelle Indian Health Unit)*

\begin{tabular}{lccccc}
\hline $\begin{array}{l}\text { BCG } \\
\text { vaccination } \\
\text { status }\end{array}$ & $\begin{array}{c}\text { Number } \\
\text { assessed }\end{array}$ & $\begin{array}{c}\text { Number } \\
\text { of TB } \\
\text { cases } \\
\text { (deaths) }\end{array}$ & $\begin{array}{c}\text { Average } \\
\text { period } \\
\text { observed } \\
\text { (years) }\end{array}$ & $\begin{array}{c}\text { Person- } \\
\text { years } \\
\text { observed }\end{array}$ & $\begin{array}{c}\text { Rate per 1000 } \\
\text { person-years } \\
\text { observation } \\
\text { TB cases } \\
\text { (deaths) }\end{array}$ \\
\hline Vaccinated & 306 & $6(2)$ & 6.58 & 2014.3 & $2.95(0.99)$ \\
Nonvaccinated & 303 & $29(9)$ & 6.07 & 1839.6 & $15.7(4.9)$ \\
\hline
\end{tabular}

*Information up to August 1947 was studied. Adapted from reference 9. TB Tuberculosis

(through collapse therapy) proven to have theoretical advantages. The excellent studies of William Dock, recently summarized by John Murray (5), established how the distribution of ventilation and perfusion in the lung determined the major site of disease and the potential benefit of sustained periods of recumbency. In the upright position, the upper lung zones have a higher oxygen tension, favouring the growth of $\mathrm{M}$ tuberculosis (an aerobe) and possibly reducing macrophage function, thereby permitting intracellular growth of bacteria. Also in the upright position, the upper lung zones have less perfusion, resulting in reduced lymphatic drainage and antigen removal. During recumbency, the opposite occurs, and conditions are less favourable for bacterial growth. 'Resting' (collapsing) the lung was predicted to close cavities and reduce local oxygen tension.

The Canadian sanatorium movement spawned a medical and public health ethos that is unsurpassed in modern times (6). Families, communities, lay organizations, government, and the medical and nursing professions were marshalled to the tasks of creating a uniquely salutary environment for the patient and preventing transmission. The single-minded devotion of so many individuals from so many walks of life was truly remarkable. Perhaps the most far-reaching effect of the Canadian sanatorium movement occurred when Saskatchewan took the unprecedented step of introducing a fully tax-supported plan for tuberculosis treatment in 1929, the success of which proved to be an important stimulus to the introduction of Medicare by Premier TC Douglas $(1,6)$.

Another notable feature of Canada's response to the disease in the first half of the 20th century was the willingness to accept BCG vaccination as a preventive measure. In this regard, they differed sharply from the Americans, who, for a variety of reasons outlined by Gryzbowski (7), chose not to accept BCG. Quite serendipitously, Calmette and Guérin, two French scientists, had discovered that when Mycobacterium bovis was grown in ox bile, its virulence was diminished. Meticulously, over several years, they performed 230 serial passages of a single isolate of the organism, sufficient for it to lose its ability to cause progressive fatal tuberculosis in a variety of laboratory animals. The attenuated bacilli did, however, induce self-limited infection, as well as its accompanying state of partial resistance to reinfection with virulent $M$ tuberculosis and $\mathrm{M}$ bovis.

Almost as soon as the vaccine strain was available from France, the National Research Council sponsored controlled trials of its safety and efficacy, which began in Quebec in 1926 (8) and in Saskatchewan in 1933 (9). Thereafter, BCG vaccination, either universal or selective, was promoted throughout Canada. So successful was BCG in First Nations children of

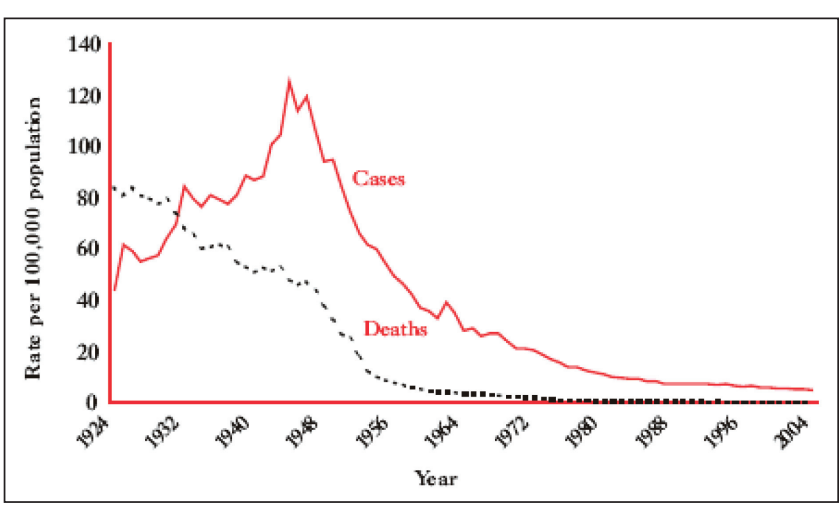

Figure 1) Tuberculosis incidence and mortality rates in Canada from 1924 to 2004. Adapted from reference 23

the Qu'Appelle Valley in Saskatchewan (Table 1) that it was widely adopted for use in First Nations and Inuit children throughout Canada (9). Local preparation of the vaccine was overseen by Dr Armand Frappier and colleagues in Montreal, Quebec (1). There followed an enormously productive inquiry into the utility of the vaccine and the tuberculin skin test, largely by scientists at McGill University (Montreal, Quebec), which continues to this day in the study of interferon-gamma release assays. More recently, the potency of BCG is understood to have waned, perhaps on account of having mutated and become less immunogenic (10).

Over the latter half of the sanatorium period, right up until the end of the Second World War, incidence rates of tuberculosis increased in Canada, presumably because there were more facilities to treat patients (official incidence figures in those days were based on admissions to hospital or sanatorium) and more inclusive admission policies (Aboriginal people, early on, were not admitted to sanatoria) (Figure 1). Meantime, mortality rates were falling, and had been since the early 19 th century - an observation variously attributed to better living standards from improved socioeconomic conditions; the application of rudimentary public health measures; the realization, through the work of Villemin and Koch, that tuberculosis was a contagious disease (and thus the introduction of isolation procedures); and probably a selection process whereby those least able to resist the infection succumbed.

\section{TUBERCULOSIS PREVENTION AND CONTROL IN THE SECOND HALF OF THE 20th CENTURY}

In 1947, before the introduction of chemotherapy, Springett (11) recorded the fate of 571 bacillary-positive cases of pulmonary tuberculosis in the United Kingdom. After four years of follow-up, $55 \%$ died, $19 \%$ remained chronically bacillary positive and $26 \%$ were rendered inactive. What happened after that in developed countries was nothing short of miraculous - the newly discovered antituberculosis drugs, prescribed in the right dosage and taken as prescribed, could be relied on to cure the disease $(12,13)$. Within decades, sanatoria were closed. But the promise of chemotherapy would fall short of expectation if the drugs were not properly used or if the societal issues, which defined the disease as much as its medical aspects, were not properly addressed. This section touches on particular aspects in that regard.

Shortly after the discovery of the first antituberculosis drug, streptomycin, in 1944, it became clear that the treatment of 


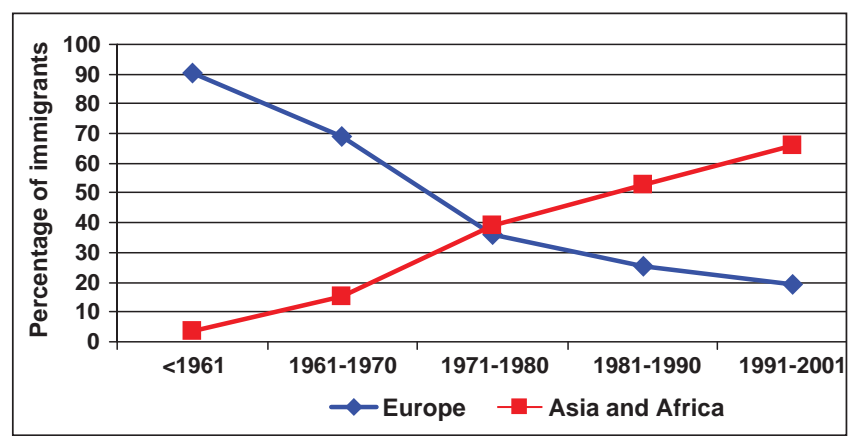

Figure 2) Percentage of immigrants from Europe, and Asia and Africa to Canada by time period. Adapted from reference 33

the disease with a single drug often failed - killing those bacteria susceptible to it but selecting out pre-existing resistant mutants in the original bacterial population by 'drug pressure' (14). Over the next several years, a range of therapeutic drugs were developed with deeper understanding of their mode of action. The end result was modern drug regimens based on superbly designed and conducted trials. Early in this process, Canadians called for urgent improvement and extension of chest clinic services, as well as a sharply increased awareness of the many pitfalls of prolonged self-medication (15). Accordingly, the concept of the 'tuberculosis dispensary' (clinic), originally developed by Sir Robert Philip in Edinburgh, United Kingdom, in 1887 in response to the limitations of mainstream medical management (16), was reinvented. The rationale for the clinic laid in proper use of the drugs, compliance with their prescription and record keeping (17). Centralization of treatment services, together with promulgation of treatment standards by the CTS, are both believed to have limited the emergence of drug resistance in the Canadian-born population (18). Failure to continue to promote the concept of clinic services may compromise tuberculosis treatment outcomes in the future (19).

In 1978, Grzybowski and Enarson (20), two of Canada's leading tuberculosis control physicians, warned of the dangers of improper use of the drugs in developing countries increased numbers of chronic excretors and drug resistance. Despite their warning and the introduction of directly observed therapy by Karel Styblo of the International Union against Tuberculosis and Lung Disease (21), large parts of the world are without effective tuberculosis control, and drug resistance is an increasingly serious problem (22). Thus, while in the 1970s there was hope of eradicating tuberculosis from the world at a price that was easily affordable, the threat now is that tuberculosis may become a multidrug-resistant disease that is too expensive to treat, except perhaps in the most affluent countries. Failure to prevent drug-resistant tuberculosis internationally is now being felt in Canada through immigration. Since the early 1960s, the country of origin of most new immigrants to Canada shifted from Western Europe to Asia and Africa (Figure 2), with the result being that an increasing proportion of tuberculosis cases are foreign-born (Figure 3) (23). Foreign birth and previous antituberculosis drug use are now the most significant risk factors for antituberculosis drug resistance in Canada (23).

In 1959, the Arden House Conference on Tuberculosis (24) in the United States inaugurated the modern tuberculosis control strategy by declaring that curative treatment of tuberculosis

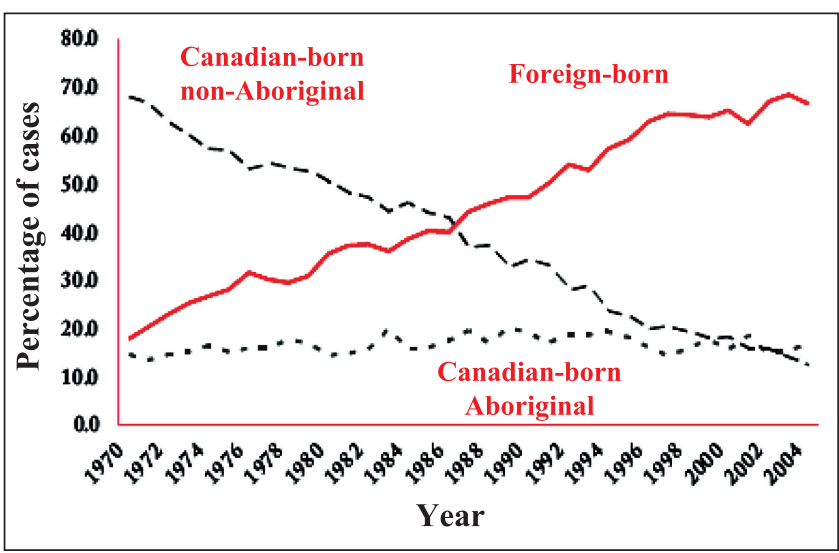

Figure 3) Proportion of tuberculosis cases by origin in Canada from 1970 to 2004. Adapted from reference 23

is a public health obligation. In the decades after the conference, tuberculosis rates in the United States decreased more slowly than forecast, perhaps because the conference's recommendations were not fully implemented until 30 years later, when an epidemic resurgence jolted the country out of complacency (25). That resurgence was most keenly felt in New York City (New York, USA), and was attributed to HIV (another major public health threat, and the single most important risk factor for the progression of recently or remotely acquired tuberculosis infection to tuberculosis disease), immigration from developing countries and the loss of dedicated funding of public health programs $(26,27)$. It included large numbers of multidrug-resistant patients. To reverse the resurgence of tuberculosis, it cost one billion dollars in public spending $(26,27)$. To quote Solomon Benatar (28), "The problem of and threat of multidrug-resistant tuberculosis within a wealthy country, such as the USA, reflects in microcosm, within one nation, the limitation of 'reductionist' approaches to 'systems' derangements which threaten health."

The power of social forces and the limitations of tuberculosis drug therapy in driving health dynamics were further illustrated in the health care experiments among the Navajo at Many Farms, Arizona (USA) (29). Despite the reduction of tuberculosis mortality due to chemotherapy and leadership within the community, tuberculosis was sustained by social circumstances. Similarly, current efforts to control tuberculosis in Aboriginal people are hampered by regional and ethnic disparities in social conditions, health conditions overall and encroachment by HIV. In Alberta, tuberculosis case rates in status Indian children both on and off reserve are 30 times higher than in other Canadian-born children. Pediatric tuberculosis is an indication of ongoing transmission (Table 2) (30). Clearly, local and specific attempts at disease control can only be partially successful. These efforts must be coupled with the acknowledgement of more profound causes and attempts to address some of the macro issues facing human progress (29).

\section{CONCLUSIONS}

By the end of the 20th century, the major battle lines in the fight against tuberculosis had shifted to developing countries, where the statistics have been and continue to be staggering: in 1990, there were 1.9 million deaths of patients older than five years of age from tuberculosis, compared with 1.1 million deaths from leprosy, malaria, tropical diseases, AIDS and 
TABLE 2

Pediatric tuberculosis case rates in Alberta by ethnic group and sex from 1990 to 2004

\begin{tabular}{llcccc}
\hline \multirow{2}{*}{ Ethnic group } & Sex & $\begin{array}{c}\text { Person-years } \\
(\times \mathbf{1 0 0}, \mathbf{0 0 0})\end{array}$ & Cases & $\begin{array}{c}\text { Crude } \\
\text { rate* }^{*}\end{array}$ & $\mathbf{9 5 \%}$ Cl \\
\hline Status Indian & Male & 2.1 & 23 & 10.74 & $6.4-15.1$ \\
& Female & 2.0 & 22 & 10.75 & $6.2-15.2$ \\
& Total & 4.2 & 45 & 10.74 & $7.6-13.9$ \\
Canadian-born & Male & 42.5 & 10 & 0.24 & $0.1-0.4$ \\
'other' & Female & 40.4 & 20 & 0.50 & $0.3-0.7$ \\
& Total & 82.9 & 30 & 0.36 & $0.2-0.5$ \\
Foreign-born & Male & 2.0 & 8 & 4.01 & $1.2-6.8$ \\
& Female & 1.9 & 13 & 6.77 & $3.1-10.5$ \\
& Total & 3.9 & 21 & 5.37 & $3.1-7.7$ \\
All ethnic groups & Male & 46.7 & 41 & 0.9 & $0.6-1.2$ \\
& Female & 44.4 & 55 & 1.2 & $0.9-1.2$ \\
& Total & 91.0 & 96 & 1.1 & $0.8-1.3$ \\
\hline
\end{tabular}

${ }^{*}$ Rate estimates are per 100,000 person-years. Adapted from reference 30

diarrhea combined (31). Much of the global pandemic is attributable to inadequately resourced programs (a reflection of the gross disparities that exist within a polarized, conflictridden, progressively dichotomized world [Figure 4]) and HIV, which, like tuberculosis, is a social disease whose patterns of transmission must be understood not only through the activity of microbes, but equally through the study of attitudes, behaviour and social organizations.

As Solomon Benatar (32) aptly proclaimed:

The problem of tuberculosis illustrates the paradox of how advances in scientific knowledge and in the ability to cure individual patients have not been accompanied by global public health gains. This is not the result of lack of knowledge but an example of lack of wisdom in the application of knowledge and a failure to appreciate the complex social and economic aspects of health and disease.

In many respects, knowledge of tuberculosis reached its apogee in the mid 20th century. That knowledge identified tuberculosis as a metaphor for social underdevelopment. We must ask what it was that allowed antituberculosis drugs to work so well in developed countries and develop a greater appreciation of our global interdependence. We must also re-visit the role of public health in the successful elimination of tuberculosis. In their prescient work, the White Plague (2), published in 1952, the Duboses were critical of exaggerated claims about

\section{REFERENCES}

1. Wherrett GJ. The miracle of the empty beds: A history of tuberculosis in Canada. Buffalo: University of Toronto Press, 1977.

2. Dubos R, Dubos J. The White Plague: Tuberculosis, Man, and Society. Boston: Little, Brown, 1952.

3. Bryder L. Below the Magic Mountain: A Social History of Tuberculosis in Twentieth-Century Britain. Oxford: Oxford University Press, 1988.

4. McCuaig K. The Weariness, the Fever, and the Fret. The Campaign against Tuberculosis in Canada, 1900-1950. Montreal: McGill-Queen's University Press, 1999.

5. Murray JF. Bill Dock and the location of pulmonary tuberculosis: How bed rest might have helped consumption. Am J Respir Crit Care Med 2003;168:1029-33.

6. Houston CS. RG Ferguson: Crusader against tuberculosis. Toronto: Dundurn Press Limited, 1991.

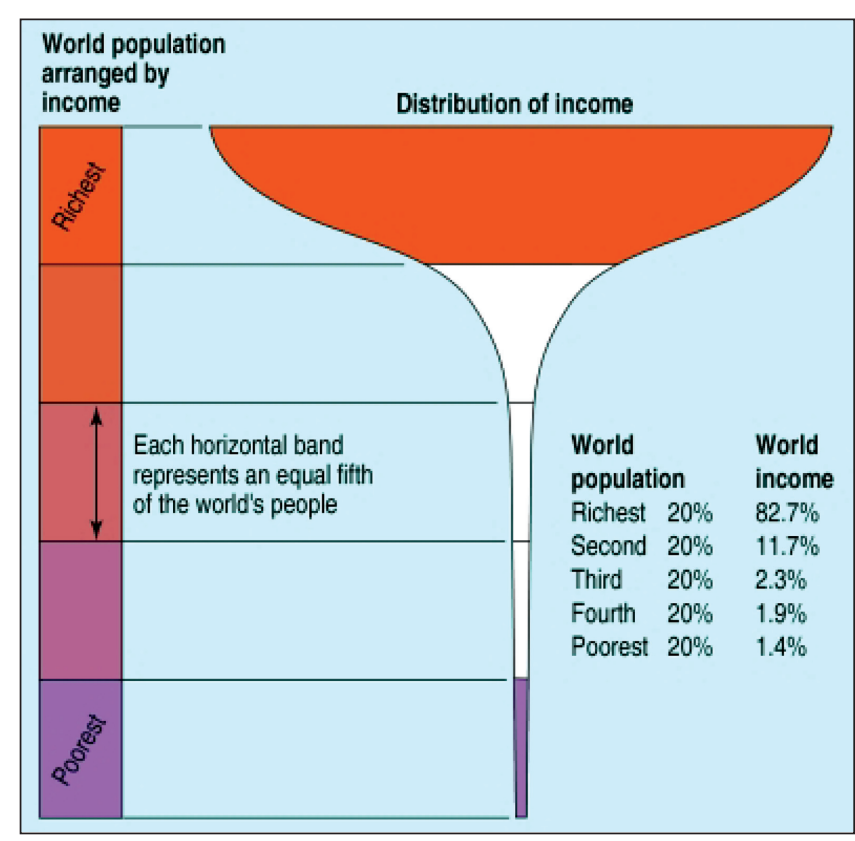

Figure 4) Champagne glass of world poverty. Adapted from reference 34

the effectiveness of solving health problems solely through medicine:

Some fifty years ago men of vision and of good will, physician and laymen, realized that tuberculosis could be conquered only by broadening the scope of conventional medical philosophy. Their efforts culminated in the educational program that enlisted the general public as an understanding and creative participant in the war against contagion. There is needed today a reawakening of the pioneering spirit that brought about first the sanitary revolution, and later the antituberculosis campaigns. Once more, it becomes urgent to force on social consciousness the realization that progress does not consist merely of doing more and more of what has proved profitable in the past.

ACKNOWLEDGEMENTS: The author would like to thank Jody Boffa and Jennifer Parlevliet of the Tuberculosis Program Evaluation and Research Unit, as well as Dr Brian McNab of the Pulmonary Division, University of Alberta, Edmonton, Alberta, for their editorial assistance. 
13. Ryan F. The Forgotten Plague: How the Battle Against Tuberculosis was Won - and Lost. Boston: Little, Brown, 1992.

14. McDermott W, Muschenheim C, Hadley SJ, Hull-Smith H, Tracy A. Streptomycin in the treatment of tuberculosis in humans. Ann Intern Med 1947;27:769-822.

15. Allen EA, Stewart M, Jeney P. The efficiency of post-sanatorium management of tuberculosis. A study of one thousand tuberculous patients discharged from sanatoria in Ontario. Can J Public Health 1964;55:323-33.

16. Keers RY. Pulmonary tuberculosis: A journey down the centuries. London: Baillière Tindall, 1978.

17. Werhane MJ, Snukst-Torbeck G, Schraufnagel DE. The tuberculosis clinic. Chest 1989;96:815-8.

18. Long R, Chui L, Kakulphimp J, Zielinski M, Talbot J, Kunimoto D. Postsanatorium pattern of antituberculous drug resistance in the Canadian-born population of western Canada: Effect of outpatient care and immigration. Am J Epidemiol 2001;153:903-11.

19. Khan K, Campbell A, Wallington T, Gardam M. The impact of physician training and experience on the survival of patients with tuberculosis. CMAJ 2006;175:749-53.

20. Grzybowski S, Enarson D. [Results in pulmonary tuberculosis patients under various treatment program conditions.] Bull Int Union Tuberc 1978;53:70-5.

21. Enarson DA. Principles of IUATLD collaborative tuberculosis programmes. Bull Int Union Tuberc Lung Dis 1991;66:195-200.

22. Anti-tuberculosis drug resistance in the world: Third global report. Geneva: World Health Organization, 2004.

<www.who.int/tb/publications/who_htm_tb_2004_343/en/> (Version current at September 6, 2007).

23. The Canadian Lung Association/Canadian Thoracic Society and Tuberculosis Prevention and Control, 2007. The Canadian
Tuberculosis Standards, 6th Edition. <www.publichealth.gc.ca/ tuberculosis $>$. (In press)

24. The Arden House Conference on Tuberculosis. U.S. Department of Health, Education, and Welfare. Public Health Service No. 784. Washington, District of Columbia: U.S. Government Printing Office, 1961.

25. Jereb J, Albalak R, Castro KG. The Arden House Conference on Tuberculosis, revisited: Perspectives for tuberculosis elimination in the United States. Semin Respir Crit Care Med 2004;25:255-69.

26. Brudney K, Dobkin J. Resurgent tuberculosis in New York City. Human immunodeficiency virus, homelessness, and the decline of tuberculosis control programs. Am Rev Respir Dis 1991;144:745-9.

27. Frieden TR, Fujiwara PI, Washko RM, Hamburg MA. Tuberculosis in New York City - turning the tide. N Engl J Med 1995;333:229-33.

28. Benatar SR. Prospects for global health: Lessons from tuberculosis. Thorax 1995;50:487-9.

29. Jones DS. The health care experiments at Many Farms: The Navajo, tuberculosis, and the limits of modern medicine, 1952-1962. Bull Hist Med 2002;76:749-90.

30. Yip D, Bhargava R, Yao Y, Sutherland K, Manfreda J, Long R. Pediatric tuberculosis in Alberta. Epidemiology and case characteristics (1990-2004). Can J Public Health 2007;98:276-80.

31. Kochi A. Tuberculosis: A Global Emergency. Geneva: World Health Organization, 1994

32. Benatar SR. Respiratory health in a globalizing world. Am J Respir Crit Care Med 2001;163:1064-7.

33. Statistics Canada. Census of Population: Immigrant population by place of birth and period of immigration. <www.statcan.ca/english/Pgdb/demo25.htm> (Version current at September 10, 2007).

34. Smith R. The Champagne glass of world poverty. BMJ 1999;318. (Edit) 


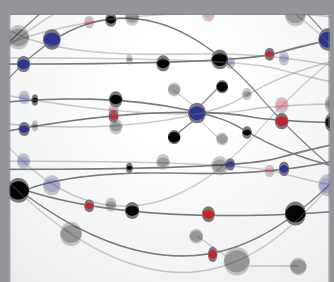

The Scientific World Journal
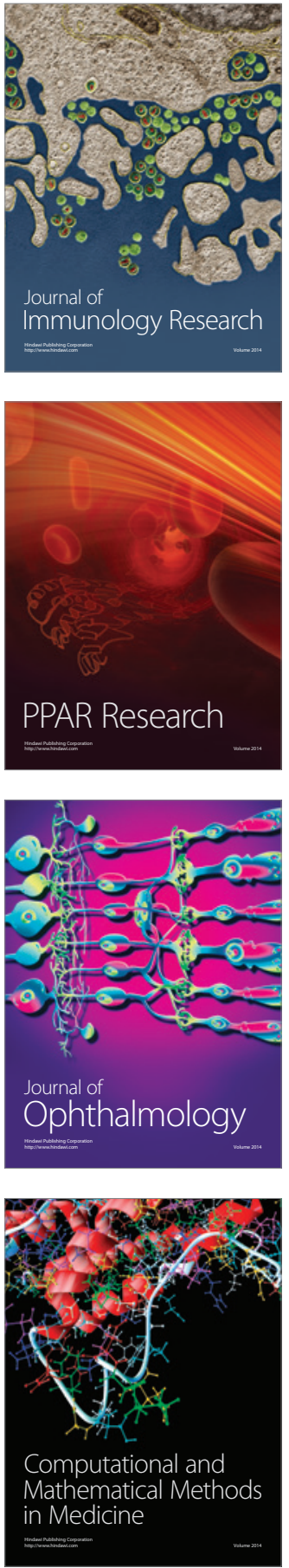

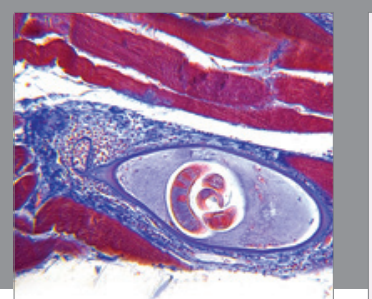

Gastroenterology Research and Practice

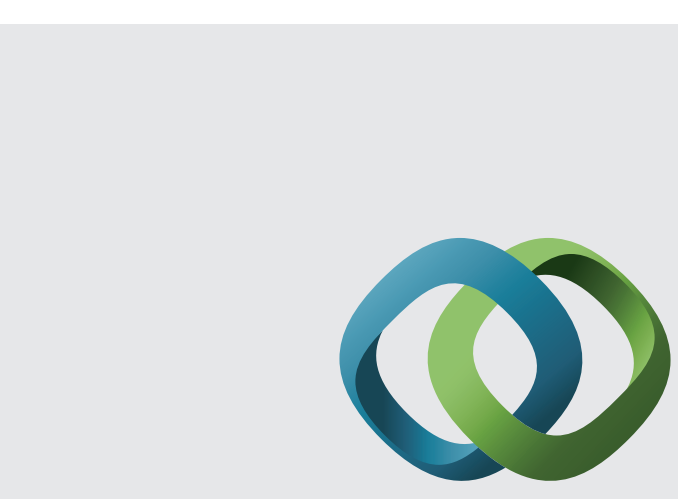

\section{Hindawi}

Submit your manuscripts at

http://www.hindawi.com
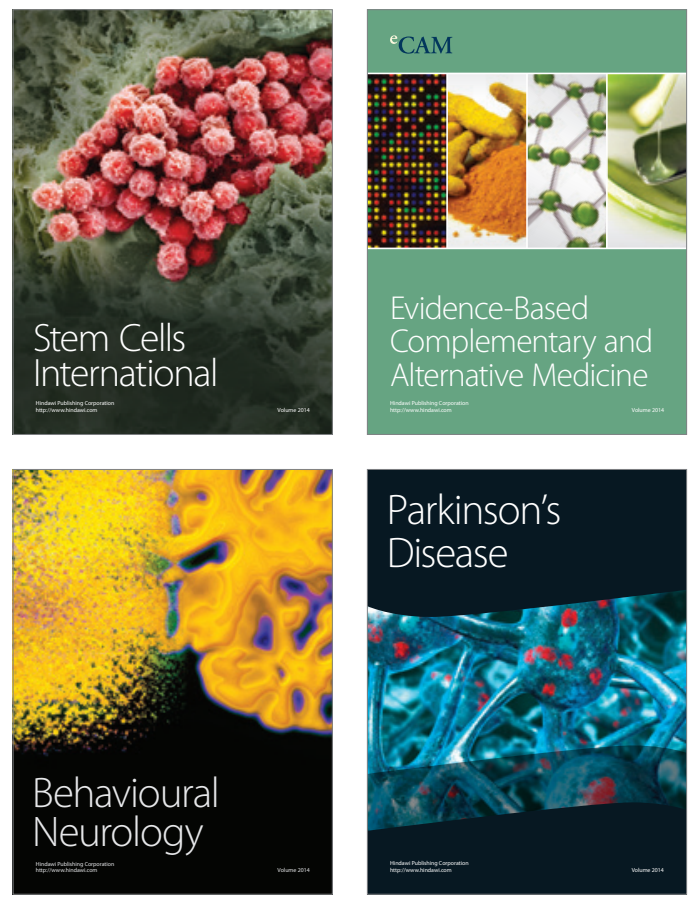
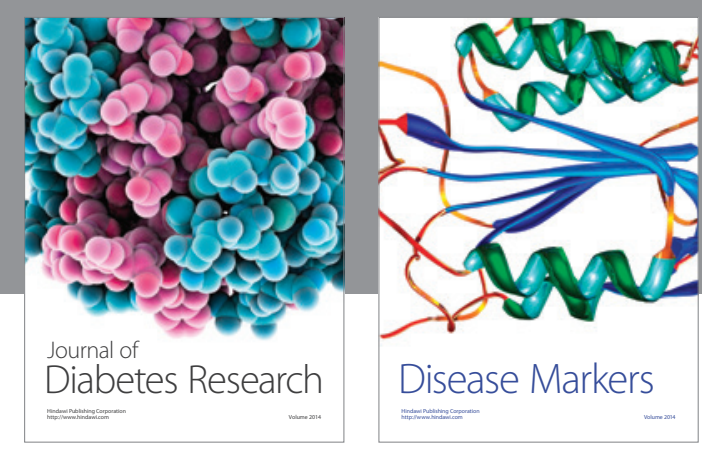

Disease Markers
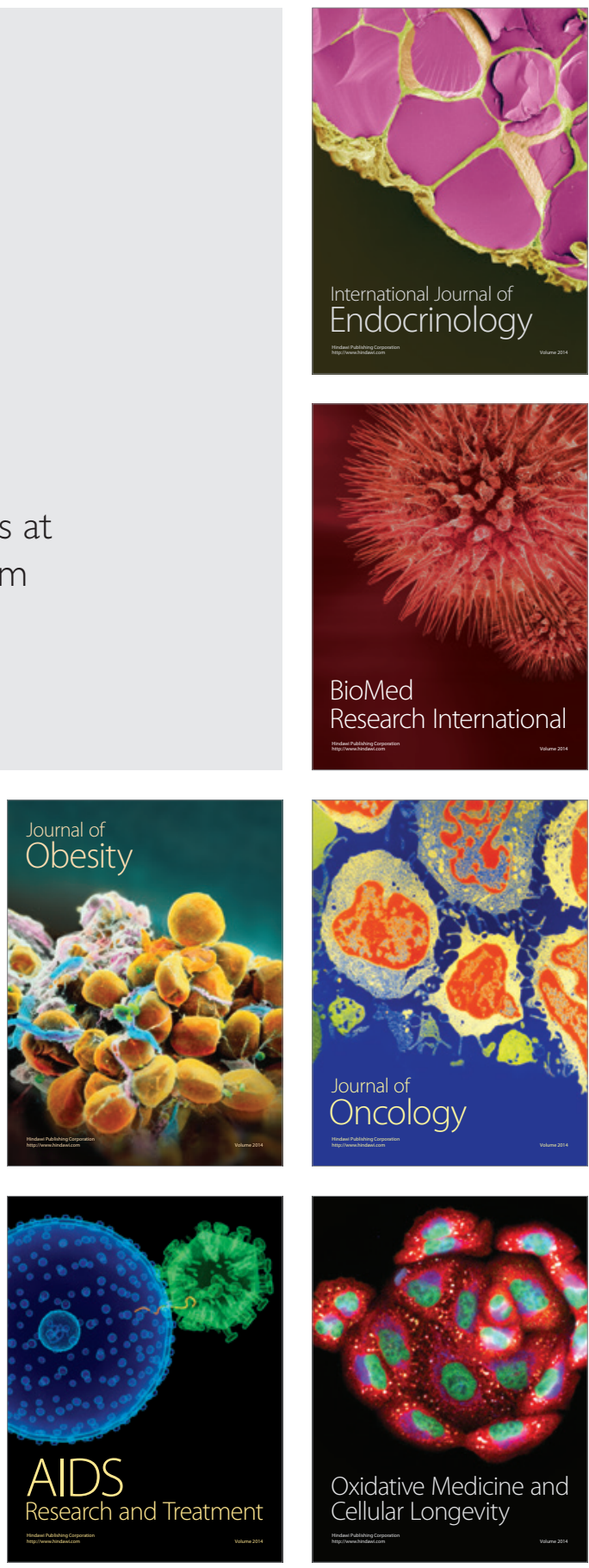